\title{
POLÍTICAS DE INTERVENÇÃO NO ENFRENTAMENTO DA VIOLÊNCIA DOMÉSTICA E FAMILIAR CONTRA A MULHER
}

\section{INTERVENTION POLICIES ON DOMESTIC VIOLENCE AGAINST WOMEN}

\author{
${ }^{1}$ Antonio Henrique Graciano Suxberger \\ ${ }^{2}$ Natália Neves Alves Ferreira
}

\section{RESUMO}

O artigo destaca a importância das políticas de caráter multidisciplinar para o enfrentamento da violência doméstica e familiar contra a mulher nos termos da Lei Maria da Penha. Desenvolve reflexão crítica sobre a efetividade das políticas de intervenção e analisa o enfrentamento dessa violência diante da proibição de suspensão condicional do processo. Vale-se de análise documental e revisão bibliográfica. As intervenções multidisciplinares devem se dar em conjunto ou mesmo dissociadas da resposta formalizada pela persecução penal e devem igualmente abranger os agressores, para que elas tenham eficácia preventiva em relação a novos episódios de violência contra a mulher.

Palavras-chave: Violência doméstica e familiar contra a mulher, Violência de gênero, Lei maria da penha, Políticas públicas, Intervenção multidisciplinar, Suspensão condicional do processo

\begin{abstract}
The article highlights multidisciplinary policies on gender based violence, acoording to the Maria da Penha Statute. It considers the context after the legal prohibition of probation during the criminal prosecution. From a literature review and document analysis, specially on researches conducted on the subject, the article sustains the importance of multidisciplinary actions combined or dissociated to formal criminal responses and focus the need of interventions considering the aggressors as well the victims, in order to assure a preventive efficiency regarding future cases of domestic violence against women.
\end{abstract}

Keywords: Domestic violence against women, Gender based violence, Maria da pena statute, Public policies, Multidisciplinary intervention, Conditional probation on criminal prosecution

\footnotetext{
${ }^{1}$ Doutor em Derechos Humanos y Desarrollo pela Universidad Pablo de Olavide, UPO, Espanha. Professor do Centro Universitário de Brasília - UniCEUB, Brasília - DF (Brasil). E-mail: suxberger@gmail.com

${ }^{2}$ Graduada em Direito pelo Centro Universitário de Brasília - UniCEUB, Brasília - DF (Brasil).

E-mail: natinaf89@gmail.com
} 


\section{INTRODUÇÃO}

A edição da Lei 11.340, em 7 de agosto de 2006, popularmente conhecida como Lei Maria da Penha, simbolizou a visibilidade da violência doméstica e familiar cometida contra a mulher e representou substancial avanço no enfrentamento da violência de gênero no país. $O$ conteúdo da Lei abrange diretrizes, normas procedimentais e materiais, regras para modelagem de políticas públicas dirigidas à intervenção no conflito, à proteção, bem assim mandamentos de estratégias, instrumentos e mecanismos de caráter assistencial, protetivo e preventivo, sem descuidar de significativa contribuição criminal na abordagem da violência de gênero.

A edição da Lei já se aproxima de um decênio. Ainda assim, o enfrentamento da violência de gênero substancia discussão recente no Brasil. De fato, na década de 1980, os movimentos feministas já representavam uma força política e social consolidada e, na mesma década, o Estado iniciou o empenho de se firmar e colaborar com documentos, compromissos e recomendações internacionais alusivos à questão. Contudo, somente no ano de 2006, a Lei Maria da Penha firmou- se como marco de visibilidade ao problema da violência de gênero e alavancou as discussões envolvendo a efetividade das políticas de intervenção dirigidas à violência doméstica e familiar contra as mulheres. Hoje, os resultados das pesquisas realizadas nesse âmbito apontam conquistas tênues na caminhada da desejada erradicação da violência de gênero.

O patriarcado que permeia a cultura das relações de poder entre homens e mulheres na sociedade, passando de uma geração para outra por meio de diferentes (e falsos) fundamentos, em nome do amor familiar, da autoafirmação no meio social ou mesmo instigada pelo consumo de álcool e entorpecentes, permanece como um dos principais óbices ao alcance da plena cidadania feminina e à igualdade material de gênero. As principais expectativas positivadas na legislação de intervenção dirigidas ao enfrentamento das agressões descritas como violência contra as mulheres têm sido a proteção das vítimas de um lado, o que é elementar e crucial, e, de outro lado, a responsabilização dos agressores.

O presente artigo busca a compreensão do mandamento constitucional de efetivação de políticas públicas dirigidas à erradicação da violência doméstica e familiar. Esta, vale frisar, é considerada em todas as suas formas, nos termos da Constituição, mas com válido destaque à violência dirigida à mulher, por força da responsabilidade assumida pelo Brasil no plano internacional. Parte-se do pressuposto de que o encarceramento dos agressores por si só não constitui medida eficaz à redução da violência, consequência que se depreende das informações 
existentes sobre o nosso sistema prisional. A preocupação deste estudo consiste em destacar a atenção a práticas orientadas segundo um enfoque multidisciplinar, que não nega tampouco se aparta da efetiva responsabilização dos agressores.

Sustenta-se que um dos instrumentos mais importantes à prevenção de práticas conflitivas reiteradas é a implementação de diversas ações de intervenção psicossocial - repitase, sem prejuízo da eventual persecução penal. Essas ações devem voltar-se tanto para as vítimas quanto para os agressores, visando à cessação do ciclo de violência entre agressor e ofendida (e eventuais dependentes), bem assim a uma chamada dos homens agressores à conscientização da ilegalidade (e inadmissibilidade) de suas ações violentas, num contexto educativo e reflexivo, que influencie na mudança cultural dessas relações sociais.

Ademais, o trabalho considera a inviabilidade de incidência da suspensão condicional do processo aos crimes previstos na Lei Maria da Penha. Com essa vedação, já presente no texto legal de 2006, mas efetivada apenas por decisões vinculantes emanadas dos Tribunais Superiores, considera-se o efeito prático pretendido pelas práticas interventivas, que é a redução ou cessação dos casos de violência doméstica contra a mulher e o estabelecimento, se o caso, de relações sadias no âmbito familiar, erigidas com base em uma prestação jurisdicional rápida e eficiente. Como efetivar políticas públicas de intervenção multidisciplinar num modelo tradicional de persecução penal, isto é, a partir da vedação de incidência de institutos despenalizantes nos casos penais de violência de gênero? A eficácia no trato dessa complexa questão, se presente uma lógica monofocal, isto é, voltada apenas à responsabilização penal do agressor, pode frustrar-se, caso as práticas interventivas pelo Estado dependam sempre da provocação inicial de órgãos de persecução penal.

A abordagem sobre o momento os estímulos aos agressores a se inserirem em programas de recuperação e reeducação, tal como estabelecidos na Lei 11.340, serão visualizadas, metodologicamente, por meio de revisão bibliográfica e documental, notadamente de pesquisas a respeito da efetividade de práticas interventivas levadas a efeito por rede intersetorial de serviços. 


\section{DESENVOLVIMENTO}

\section{Aspectos gerais da Lei Maria da Penha}

Em vigor desde o dia 22 de setembro de 2006, a Lei Federal 11.340/2006 recebeu o nome de Lei Maria da Penha em homenagem à vítima que representou um marco no cenário nacional de enfrentamento da violência contra as mulheres. Maria da Penha foi vítima de violências perpetradas por seu marido, particularmente em 1983, quando sofreu duas tentativas de homicídio que resultaram na sua paraplegia. Buscou a responsabilização de seu agressor, especialmente a sua prisão, que somente ocorreu após a condenação do Estado brasileiro por negligência e omissão em relação à violência doméstica e familiar contra a mulher na Comissão Interamericana de Direitos Humanos da OEA (Organização dos Estados Americanos). Com essa condenação, o Brasil foi obrigado a cumprir uma série de recomendações dentre as quais se destaca a criação de uma legislação específica para tratar desse tipo de violência. A Lei Maria da Penha, então, estabeleceu "mecanismos para coibir a violência doméstica e familiar contra a mulher", conformando o preceito estabelecido no $\S 8$. $^{\circ}$ do artigo 226 da Constituição Federal e materializando as determinações veiculadas tanto na Convenção sobre a Eliminação de Todas as Formas de Discriminação contra as Mulheres (1979) quanto na Convenção Interamericana para Prevenir, Punir e Erradicar a Violência contra a Mulher (1994). Além disso, trouxe igualmente disposições sobre "a criação dos Juizados de Violência Doméstica e Familiar contra a Mulher", além de promover alterações nos Códigos Penal e de Processo Penal e na Lei de Execução Penal.

Se a Constituição determina, por um lado, que o Estado providencie a assistência à família, "na pessoa de cada um dos que a integram, criando mecanismos para coibir a violência no âmbito de suas relações" (BRASIL, 1988, artigo 226, § 8. ${ }^{\circ}$ ), por outro lado, são as Convenções internacionais específicas sobre o tema da violência de gênero, de que o Brasil é país signatário, que estabelecem o mandamento normativo para a promoção de meios de enfrentamento desse tipo de violência especificamente contra a mulher.

A Convenção sobre a eliminação de todas as formas de discriminação contra a mulher, de 1979, intitulada $C E D A W$, nome resultante da abreviatura do título da Convenção em língua inglesa, positiva a igualdade material entre os gêneros masculino e feminino e estabelece, entre outras importantes medidas, o dever de adotar "medidas adequadas, legislativas e de outro caráter, com as sanções cabíveis e que proíbam toda discriminação 
contra a mulher" (ONU, 1979, artigo 1. ${ }^{\circ}$, n. 2). A Convenção Interamericana para prevenir, punir e erradicar a violência contra a mulher, nominada como "Convenção de Belém do Pará", de 1994, adotada pelo Brasil, em 9 de junho de 1994, no Vigésimo Quarto Período Ordinário de Sessões da Assembleia Geral da Organização das Nações Unidas, estabelece especialmente em seu artigo 7. uma série de obrigações de caráter normativo para que o Estado brasileiro promova medidas de erradicação da violência contra a mulher (OEA, 1994).

Para além das obrigações normativas, a efetiva edição da Lei Maria da Penha responde ao amplo movimento social de defesa dos direitos da mulher com o objetivo de erradicar obstáculos à plena cidadania feminina e imprimir igualdade material de gênero. A histórica posição de inferioridade da mulher na sociedade brasileira reforçou — e ainda reforça - a necessidade de repensar formas mais efetivas de enfrentamento desse grave fenômeno social. Sua concretização insere- se na conexão de distintas políticas públicas, dirigidas à promoção da igualdade nas relações de trabalho, na saúde, na garantia da autonomia econômica das mulheres, entre outras (CUNHA, 2010).

De acordo com pesquisa divulgada pela Fundação Perseu Abramo, em 2010, a cada minuto quatro mulheres são espancadas no Brasil (MORIÉRE, 2011). No ano de 2012, a Central de Atendimento à Mulher (Ligue 180) registrou 201.569 chamadas, sendo que 24. 775 ligações referiam-se a casos de violência, dentre os quais $98,9 \%$ dos casos de violência foram praticados por homens, $69,7 \%$ realizados por companheiros e cônjuges das vítimas e 2,4\% por namorados (INESC, 2012). O país ocupa a sétima posição em um ranking de 84 nações com maior índice de assassinatos de mulheres no mundo, com uma taxa de 4,4 mortes em 100 mil, segundo dados do Mapa da Violência 2012 (WAISELFISZ, 2012). Tais dados são incompatíveis com os anseios de um Estado Democrático de Direito, que prega a construção de uma sociedade justa e solidária, que erigiu a dignidade da pessoa humana como princípio fundamental. Segundo tal dicção normativa, não deveria haver espaço ou margem a opressões e exclusões de gênero. Ao revés, impõe-se, mediante um olhar multidisciplinar, a identificação das especificidades de cada um, independentemente de sexo, religião, credo e raça.

Diante do novo cenário democrático do país, é indiscutível a contribuição impulsionada pelo movimento das mulheres para a Constituição Federal de 1988. O ordenamento jurídico passou a prever diversos dispositivos consagrando a igualdade entre mulheres e homens: estabelecendo ao Estado o ônus de assegurar igualdade entre homens e mulheres em relação a direitos e deveres decorrentes da sociedade conjugal e outras entidades familiares (artigo 226, $\S \S 3^{\circ}, 4^{\circ}$ e $5^{\circ}$, da Constituição Federal); direitos da mulher relativos ao trabalho (artigo $7^{\circ}$, 
incisos X e XXX, da Constituição Federal); igualdade entre homens e mulheres na aquisição da propriedade (artigo 183, § $1^{\circ}$ e artigo 189, parágrafo único, ambos da Constituição Federal); direitos relativos à proteção da maternidade (artigo $6^{\circ}$; artigo $7^{\circ}$, inciso XVIII; artigo 201, inciso II; artigo 203, inciso I, todos da Constituição Federal e artigo 10, inciso II, alínea "b" do Ato das Disposições Constitucionais Transitórias), entre outros.

A iniciativa das instâncias estatais para colocar em prática o que há alguns anos haviam se comprometido mostrou-se, desafortunadamente, tardia: observar os princípios e implementar programas aprovados pelas Convenções como parte de suas políticas. Ao se considerar as datas da CEDAW e da Convenção de Belém do Pará e o ano de edição da Lei Maria da Penha, é inegável a postura leniente do Estado brasileiro em face do enfrentamento do gravíssimo problema da violência contra a mulher (CUNHA, 2010). Conquanto tardio, o diploma legal ainda veio em boa hora.

Nessa perspectiva, a Lei n. 11.340/2006 afastou a aplicação da Lei dos Juizados Especiais (Lei n. 9.099/1995) que acabou abarcando grande parte dos conflitos em questão. Conquanto o fenômeno da violência de gênero manifeste-se por meio de ciclos de violência, suas adequações típicas muitas vezes guardam correlação com as chamadas infrações de menor potencial ofensivo e, por conseguinte, atraiam a competência do Juizado Especial Criminal tal como previsto na Lei 9.099 de 1995. Esta estimula a composição civil dos danos experimentados pelo ofendido e prima pela incidência de respostas estatais despenalizantes, isto é, que afastem o estigma da persecução penal formalizada por meio do processo judicial e também a previsão de acordos que assegurem maior presença do ofendido no sistema de justiça criminal.

A incidência da Lei 9.099 aos casos de violência doméstica e familiar contra a mulher, entretanto, mostrou-se desastrosa. Para além da consideração das práticas violentas como de "menor potencial ofensivo", o que contraria frontalmente as disposições da CEDAW e da Convenção de Belém do Pará, as respostas obtidas pelos Juizados Especiais Criminais resultavam, usualmente, na simples determinação de distribuição de cestas básicas em entidades assistenciais sem a incidência de políticas de intervenção específicas ao conflito doméstico e familiar. Os Juizados Especiais Criminais, portanto, pela má utilização de alguns bons recursos de que dispunha, colaboraram para a banalização da violência doméstica e para a propagação da ideia de que o Judiciário seria incapaz de intimidá-la ou mesmo prevenila.

Dessa forma, diante das novas diretrizes, foi promulgada a Lei Maria da Penha que criou mecanismos com para coibir, prevenir e erradicar a violência de gênero, com a finalidade 
de garantir à mulher sua integridade física, psíquica, sexual, moral e patrimonial. A Lei previu a criação dos Juizados de Violência Doméstica e Familiar contra a mulher; estabeleceu medidas protetivas de urgência, como o afastamento do agressor do lar ou do local de convivência e, entre outras, a proibição de contato e de aproximação da ofendida, além de sublinhar a possibilidade de o Juiz, para assegurar a efetividade da medida protetiva, decretar a prisão processual do agressor.

Após quase dez anos da vigência da Lei, pesquisas revelam que a maioria da população conhece a Lei Maria da Penha (IBOPE; THEMIS, 2008), resultado que se atribui aos meios de comunicação, ao ativismo dos movimentos sociais, da promoção de estudos e estatísticas. A presença da Lei representa força política apta a promover o início da transformação do sistema social ainda fortemente marcado pelo patriarcado.

Ainda que as pesquisas apontem o crescimento da conscientização social sobre o problema das mulheres em situação de violência, a busca por caminhos e inspirações mais eficazes para a proteção da comunidade feminina há de ser uma constante. Estudo realizado pelo IPEA, em março de 2015, divulgou dados ainda tímidos sobre a efetividade da Lei Maria da Penha. O índice de homicídios de mulheres, por exemplo, diminuiu 10\% desde a vigência da Lei no ano de 2006 (CERQUEIRA, 2015). A complexidade da questão da violência doméstica e familiar contra a mulher responde em grande medida pela dificuldade de enfrentamento do fenômeno.

De acordo com estudos realizados nesse campo, na percepção da sociedade civil, o consumo de álcool e o ciúme são os principais responsáveis pelas agressões domésticas contra a mulher. Pesquisas revelam ainda que as vítimas atribuem a violência sofrida à separação, traição conjugal, problemas econômico- financeiros, uso de drogas, influência de familiares e amizades (BIANCHINI, 2012). O problema demanda uma ação multidisciplinar do aparelho Estatal, exige a participação efetiva do Poder Judiciário, de instituições essenciais à realização da Justiça como o Ministério Público e a Defensoria Pública, do reforço das Delegacias Especializadas, de organismos governamentais e não governamentais encarregados de promover ações em favor dos direitos das mulheres, do empenho de vários profissionais como psicólogos, médicos, assistentes sociais.

Nesse sentido, a Lei estabelece diretrizes para que a União, Estados, Distrito Federal e Municípios criem e promovam centros de atendimento multidisciplinar para as vítimas e para os agressores, centros de educação e reabilitação para os agressores, programas e campanhas de enfrentamento da violência doméstica e familiar e uma sucessão de serviços 
especializados à mulher (casas-abrigos, serviços de saúde, centros de perícia médico-legal qualificados, etc.) (artigo 35). Igualmente, prevê a necessidade de criação do Juizado da Mulher; assistência jurídica; equipe de atendimento multidisciplinar, integrada por profissionais especializados nas áreas psicossocial, jurídica e de saúde (artigos 27 a 32). Também promoveu alteração na Lei de Execuções Penais, para estabelecer que, nas hipóteses de execução de pena restritiva de direitos de limitação de fim de semana, o Juiz poderá determinar o comparecimento obrigatório dos agressores a programas de recuperação e reeducação.

Também a Lei 11.530, de 24 de outubro de 2007, que institui o Programa Nacional de Segurança Pública com Cidadania - PRONASCI, dá particular atenção à questão da violência doméstica e familiar contra a mulher. A Lei estabelece quatro focos prioritários de atuação: o foco repressivo, o foco etário, o foco territorial e o foco social. Dentro do foco social, os programas, projetos e ações que compõem o PRONASCI devem dirigir-se prioritariamente a “jovens e adolescentes egressos do sistema prisional ou em situação de moradores de rua, famílias expostas à violência urbana, vítimas da criminalidade e mulheres em situação de violência" (artigo 4..$^{\circ}$, inciso II).

Assim, relativamente ao arcabouço normativo, vê-se que o enfrentamento da violência doméstica e familiar contra a mulher, respeitada a complexidade do fenômeno, mostra-se bem resguardado. Esse feixe de preceitos normativos, entretanto, reflete uma prática de efetiva intervenção estatal nesses conflitos?

\section{Políticas de intervenção estabelecidas nos dispositivos da Lei}

Na medida em que o arcabouço normativo que versa sobre violência doméstica e familiar contra a mulher traz uma série de previsões que se referem às políticas públicas de intervenção nesses conflitos, é possível visualizar essas práticas interventivas dissociadas dos processos em que se promove a responsabilização penal do agressor? Em outras palavras, é possível fazer política pública de intervenção sem que isso nada se relacione com a repercussão penal dos fatos ensejadores da violência? Esses questionamentos traduzem preocupação que, se proibidas medidas despenalizantes no curso da persecução penal em casos de violência doméstica e familiar contra a mulher, devem orientar os rumos da persecução penal doravante.

Parcela do movimento feminista já constatou a impropriedade do olhar voltado estritamente à tendência punitivista para enfrentamento do problema da violência de gênero. Nesse sentido, Bárbara Musumeci Soares (2012) indaga: 
Quais têm sido as principais formas de intervenção direta adotadas em vários países, inclusive o nosso, no enfrentamento das agressões, crônicas e agudas, descritas como violência contra a mulher? Proteger as vítimas, de um lado, o que é indiscutivelmente necessário e primordial, e, de outro, endurecer punições para os agressores, como instrumento jurídico e político de combate à impunidade. O primeiro aspecto vale por si mesmo, independentemente de resultados agregados mensuráveis. Já o segundo é menos óbvio, pois, como vimos, não se tem qualquer indicação sobre os efeitos dissuasórios dos métodos punitivos adotados. Não há, até o momento, pesquisas sobre os impactos reais das medidas restritivas de liberdade, assim como não se conhecem, para esses casos, os efeitos de soluções alternativas à prisão, como prestações pecuniárias ou de serviços. Contudo, ainda que não se possa descartar, de antemão, a hipótese de que as prisões em flagrante (que, desde 2006, vêm sendo efetuadas com base na Lei Maria da Penha) contribuam para reduzir a violência, tudo o que se sabe até hoje sobre nosso sistema prisional nos leva a acreditar exatamente no contrário.

\begin{abstract}
A ideia de que algumas noites ou meses passados em uma cela possam transformar um autor de violência doméstica em uma pessoa mais pacífica e respeitosa aos direitos alheios não parece muito realista. Tanto mais se o preso obedecer ao script da dominação viril, que, no ambiente prisional, encontrará as condições mais favoráveis para se exacerbar. Por isso é tão importante que se comece a avaliar os impactos reais das prisões provisórias previstas na Lei brasileira em vez de continuarmos atuando como se a privação de liberdade, frequentemente indesejada pelas próprias mulheres agredidas, fosse um fim em si mesmo e uma solução adequada à violência conjugal.
\end{abstract}

A crítica se faz baseada em experimentos e observações realizadas de forma articulada com o nosso sistema jurídico e o sistema jurídico no plano internacional, revelando dados não muito animadores capazes de inibir a violência doméstica.

Não se trata de abrir mão da responsabilização dos agressores, mas é importante salientar que de nada adianta responsabilizá-los como resposta punitiva única sem se considerar a necessidade de uma política intervencionista naquele conflito de modo mais amplo, multidisciplinar, tanto para as vítimas quanto para os agressores - acompanhamento psicológico, acolhimento da ofendida, serviços de saúde e outras questões.

Além disso, ao analisar as penas aplicadas para os crimes, a sensação que se transmite é de impunidade, dada a consideração em geral de penas que dificilmente se traduzem em recolhimento à prisão. São os casos dos crimes de ameaça e de lesão corporal, cujos preceitos sancionatórios ou redundarão na substituição por penas restritivas de direitos ou redundarão em cumprimento da reprimenda em regime domiciliar, por força do crônico problema atinente à ausência de estabelecimentos prisionais adequados ao cumprimento da pena em regime aberto. Com isso, em estrita observância às disposições do Código Penal, a ausência de recolhimento à prisão reflete o enfraquecimento do esforço dirigido à adoção de um arcabouço jurídico mais rígido para estimular as transformações ou prevenção dos comportamentos violentos. Tal cenário reforça a necessidade de implementação de políticas públicas com base numa atuação multidisciplinar aliada à responsabilização dos agressores. 
Vale lembrar que, a despeito de as medidas repressivas estarem sendo privilegiadas na resolução dos casos concretos, a Lei Maria da Penha dispõe também de uma série de diretrizes, normas e políticas públicas de caráter não punitivo.

A intervenção da Lei consiste na punição do agressor, prevenção à violência e assistência às vítimas. A rede de atendimento às mulheres em situação de violência é composta por serviços de Casas-Abrigo, Delegacias Especializadas de Atendimento à Mulher (DEAMs), Defensorias da Mulher, Juizados de Violência Doméstica e Familiar, Central de Atendimento à Mulher - Ligue 180, serviços de saúde voltados para o atendimento dos casos de violência sexual e doméstica e outros análogos.

Quanto à abordagem da lei ao tratamento dos agressores, há alguns dispositivos que se encontram à margem do viés exclusivamente punitivista. São exemplos dessa assertiva o artigo 30 e inciso $\mathrm{V}$ do artigo 35, que estabelecem a criação de centros de educação e de reabilitação para os agressores a critério dos entes federativos. Por sua vez, o artigo 45 da Lei 11.340 promoveu alteração no artigo 152 da Lei de Execuções Penais, para estabelecer a possibilidade de o Juiz determinar o comparecimento obrigatório dos agressores a programas de recuperação e reeducação.

A Lei Maria da Penha, em que pese a constatação geral de necessidade de ações que também incluam os agressores, máxime para a cessação de ciclos de violência entre casais ou núcleos familiares que permanecem em convivência mesmo após a chamada ao sistema de justiça criminal, está a indicar que as ações de intervenção apresentam lacunas: primeiro, não fazem nenhuma alusão a trabalhos de prevenção com a população masculina; segundo, não apresentam uma definição clara sobre a estrutura e organização dos centros de atendimento aos autores de violência, cuja finalidade, conforme a lei, seria "educação e reabilitação" (artigo 35) ou "recuperação ou reeducação" (artigo 45). Essa parcimônia legislativa produz consequências na interpretação ambígua das unidades de tratamento dos agressores, gerando uma opacidade dos objetivos desses programas diante dos anseios sociais: garantia dos direitos das mulheres, punição dos agressores e "recuperação e reeducação" deles (PRATES, 2013).

Como destacam Ana Luiza Branco e Tânia Almeida (2012, p. 94), a integração desses interesses sociais criou a necessidade de um novo paradigma de justiça, que inclui o trabalho preventivo ou educativo com os autores de violência. Baseado no modelo prevencionista, esse modelo de justiça tem o pressuposto de que a pena deveria possuir a finalidade de prevenir a ocorrência de outros delitos. Dessa forma, as penas alternativas passam a ser mecanismos que privilegiam formas alternativas ao cárcere para a responsabilização criminal. 
É de suma importância efetivar ações em políticas públicas ajustadas à complexidade do problema. Tomem-se como exemplos: a prevenção da violência voltada para os homens nas diversas faixas etárias (atenção para os brinquedos e meios de entretenimento, atividades na escola voltadas para a não-violência); criação de uma política organizacional que permita aos centros de atendimento aos autores de violência, nos exatos termos do artigo 35 da Lei, participar da reintegração destes homens à sociedade através da reeducação assistida por profissionais devidamente qualificados; serviços de saúde que atuem como ponto de partida para os casos de violência contra as mulheres; o fundamento do cuidado e da completude das ações garantam também aos homens serem ouvidos em suas necessidades e pleitos sobre os atos violentos.

Os dados apresentados no relatório final da Comissão Parlamentar Mista de Inquérito, instalada "com a finalidade de investigar a situação da violência contra a mulher no Brasil e apurar denúncias de omissão por parte do poder público com relação à aplicação de instrumentos instituídos em lei para proteger as mulheres em situação de violência", cujas atividades se realizaram no ano de 2013, são alarmantes nessa linha de preocupação. Segundo a Comissão, são poucos os Estados que contemplam o serviço de reeducação para homens autores de violência. Grande parte dos Estados não possui sequer uma unidade desse tipo, como, por exemplo, os Estados de Alagoas, Amapá, Bahia, Paraná, entre outros. Já alguns relatam a existência de apenas um núcleo voltado à educação dos agressores, a exemplo dos Estados do Maranhão, Acre, Amazonas, Ceará, Minas Gerais. Diante dos inúmeros dados que impressionam ao se ler o relatório, à exceção do Estado de São Paulo que registrou a existência de dois núcleos de responsabilização e educação dos agressores, nos demais Estados, a única unidade desse tipo se encontra nas capitais (BRASIL, SENADO FEDERAL, 2013). Essa informação, mais uma vez, conduz ao sentimento de descaso, impunidade, banalização e desigualdade no empenho das políticas públicas de enfrentamento à violência contra as mulheres no Brasil.

Dados de trabalho realizado pelo IPEA, no ano de 2015, com a finalidade de avaliar a efetividade da Lei Maria da Penha, indicam a não uniformidade no país de sua eficiência. Decerto, essa eficiência depende da institucionalização dos serviços protetivos nas diversas localidades do território de forma uniforme, levando-se em consideração as especificidades de cada região e a diversidade cultural da população. Assim, é de se questionar o interesse do poder público na mantença do atual estado das coisas nas localidades em que não há mobilização para implantar e efetivamente colocar em prática as políticas prescritas. Além disso, nos locais 
em que há políticas públicas em prática, de que adianta o Estado dotar-se de tantos instrumentos normativos se a realidade aponta a falta de estrutura física, a falta de mão de obra capacitada no trato destas questões, o cansativo mecanismo burocrático que rege as instituições em geral, a falta de celeridade nos processos criminais?

O grande desafio é a indicação de estratégias de ação no curso de um processo jurídico que propiciem o encaminhamento dos agressores a programas de acompanhamentos psicossociais e outras medidas alternativas de responsabilização e conscientização, não apenas quando da aplicação da pena, mas também antes de sua responsabilização. A intervenção deve ser rápida e eficiente, a fim de afastar o agressor do contexto de violência, proteger a vítima e seus dependentes, prevenindo a continuidade das agressões. Não há como deixar de lado as implicações que esse problema traz para as mulheres deixando de lado os homens. Como bem destaca Heleieth Saffioti:

\begin{abstract}
As pessoas envolvidas na relação violenta devem ter o desejo de mudar. É por esta razão que não se acredita numa mudança radical de uma relação violenta, quando se trabalha exclusivamente com a vítima. Sofrendo esta algumas mudanças, enquanto a outra parte permanece o que sempre foi, mantendo seus hábitos, a relação pode inclusive, tornar-se ainda mais violenta. Todos percebem que a vítima precisa de ajuda, mas poucos vêem esta necessidade no agressor. As duas partes precisam de auxílio para promover uma verdadeira transformação da relação violenta. (SAFFIOTI, 2004, p. 53)
\end{abstract}

Apesar de a Lei Maria da Penha possibilitar a criação de atendimento psicossocial às mulheres agredidas e também do atendimento psicossocial aos agressores, ela não delineia caminhos para viabilizar a imediata condução. A violência doméstica é um problema complexo e social, advindo de relações familiares. Por isso, a urgência na cessação da violência. Se as intervenções só se derem a partir da sentença e execução penal, os riscos serão muitos. Além de punir, a intervenção estatal há de focar no efetivo amparo e na segurança das vítimas, bem como atuar de maneira legítima no tratamento dos agressores, para que repensem nas atitudes violentas como forma de superação (ou, ao menos, evitação) dos problemas oriundos das relações de afetividade e, principalmente, estabelecer as bases para uma mudança cultural que se reflita em crianças e adolescentes formados no seio familiar desses agressores e mulheres agredidas. 


\section{A INTERVENÇÃo ESTATAL DIANTE DA PROIBIÇÃo DE INCIDÊNCIA DO INSTITUO DA SUSPENSÃO CONDICIONAL DO PROCESSO}

A Lei Maria da Penha explicitou em seu artigo 41 a inviabilidade de incidência da Lei dos Juizados Especiais (Lei 9.099 de 2005) aos crimes praticados em situação de violência doméstica e familiar contra a mulher. Dado que o instituto da suspensão condicional do processo encontra previsão no artigo 89 da Lei 9.099, ao se interpretar literalmente o dispositivo, entende-se pelo afastamento de sua aplicação nos processos judiciais criminais de violência doméstica e familiar contra a mulher, ainda que o patamar sancionatório do crime amolde-se ao que dispõe o mencionado artigo 89. A suspensão condicional do processo é um instituto jurídico despenalizador.

Consiste, genericamente, numa forma de composição do conflito de interesses penal
que não dependa de ficar demonstrada a existência de infração penal e
responsabilidade do processado (pela produção de provas). Trata-se de medida
consensual em que o réu se compromete a adotar determinadas atitudes que o autor
julga suficientes e que resolve definitivamente o conflito.(CARVALHO, 2003, p. 258)

Para corroborar a aplicação literal do artigo 41 da Lei Maria da Penha, o Supremo Tribunal Federal, no julgamento da Ação Direta de Inconstitucionalidade (ADI) 4424, de Relatoria do Ministro Marco Aurélio, salientou que o artigo 41 da Lei 11.340/06 é constitucional e defendeu esta posição como a mais coerente com os princípios constitucionais e com as Convenções internacionais sobre o tema. Além disso, o mesmo Tribunal, ao julgar a Ação Declaratória de Constitucionalidade (ADC) 19, igualmente validou o artigo 41 da Lei Maria da Penha.

Mesmo diante da vedação, diversos aplicadores e estudiosos do direito, insistiram no oferecimento da proposta de suspensão condicional do processo para infrações realizadas em situação de violência doméstica e familiar contra a mulher. Tal entendimento reforçava a ideia de que a suspensão condicional do processo poderia ser um instrumento eficaz e que, se bem utilizado, seria hábil a construir relações domésticas estáveis e sadias, bem como representar a efetividade e a agilidade da atividade jurisdicional do Estado, se manejada como medida educativa e dirigida a se prestar como importante instrumento no tratamento de problemas psicológicos e sociais do agressor e da vítima.

O instituto da suspensão condicional do processo surgiu com a finalidade de dar eficiência prática ao direito processual, demonstrando a necessidade de uma mudança legislativa capaz de atenuar as dificuldades existentes no nosso sistema de justiça como: 
sobrecarga de processos, morosidade na solução das causas, excessiva burocracia dos serviços dos juízos e tribunais (FERNANDES, 2010). Trata-se de um meio alternativo para afastar a necessidade de um procedimento penal.

A fim de apartar as controvérsias trazidas pela vedação legal do artigo 41, o Superior Tribunal de Justiça, em 10 de junho de 2015, aprovou o enunciado 536 de sua Súmula, cujo texto assim dispõe: “A suspensão condicional do processo e a transação penal não se aplicam na hipótese de delitos sujeitos ao rito da Lei Maria da Penha".

É justamente na consolidação da compreensão da vedação legal de suspensão condicional do processo que reside a preocupação do presente trabalho. É certo que a intervenção estatal no conflito de violência doméstica e familiar contra a mulher que chega ao sistema de justiça criminal não se condiciona ou não se subordina a favores legais concedidos ao agressor previamente ou no curso da persecução penal. Contudo, se o êxito de programas e iniciativas dirigidas à prevenção ou a superação de contextos violentos tem por pressuposto a voluntariedade na participação do agressor, como trabalhar essa voluntariedade sem a contrapartida de benefícios legais incidentes na persecução penal?

Não se pretende com isso fazer uma defesa do instituto, em si, da suspensão condicional do processo. Até porque sua simples incidência, dissociada de uma prática estatal de intervenção no conflito e de efetivo acolhimento da ofendida, mostra-se pouco efetiva em face da pretendida prevenção de novos casos de violência.

A vedação de suspensão condicional do processo, na medida em que impede a simplificação e a agilidade dos processos - máxime porque, se exitosa em sua pretensão despenalizante, permite solução processual que torna desnecessária a realização de instrução processual em juízo -, culmina na ultimação de todo o processo-crime como regra geral na persecução penal dos casos de violência doméstica e familiar contra a mulher. É sabido que, para a desobstrução dos sistemas de justiça e carcerário, mostra-se importante o estímulo ao uso de vias alternativas para a solução dos litígios. A partir daí, emergem questões inquietantes dignas de reflexão: o momento de se estimular os agressores a se inserirem nos programas de recuperação e reeducação dispostos na lei não seria durante a suspensão condicional do processo? Como estimular os agressores sem qualquer favor legal que resulte em benefício prático no campo processual? Mostra-se eficaz continuar tratando essa situação estritamente do ponto de vista da resposta formalizada pelo processo criminal tradicional, ou seja, por meio do trinômio "processo, instrução, condenação"? Como compatibilizar políticas de intervenção 
com um modelo tradicional de persecução penal em situações de incidência da Lei Maria da Penha?

É importante frisar que a realização de ações de cariz multidisciplinar guarda mais proximidade com a presença de recursos humanos e materiais compatíveis com essa preocupação que efetivamente com a presença de institutos despenalizantes ou de caráter processual. Afinal, a incidência dessas intervenções de caráter mais amplo referem-se à cessação dos chamados ciclos de violência e igualmente à preocupação com a prevenção de novos episódios de violência contra a mulher. É certo que há a preocupação atinente ao fato criminoso ensejador da intervenção estatal, mas de plano se vê que a intervenção como um todo assume uma preocupação mais ampla que a simples solução específica daquele caso ou processo instaurado a partir da notícia de crime.

A par da discussão específica sobre a suspensão condicional do processo, vale anotar que o Observatório da Lei Maria da Penha, nos anos de 2010 e 2011, apurou que a criação de instâncias especializadas não tem, na realidade, resultado numa aplicação integral da lei. Em diversas unidades da Federação, a instalação dos Juizados de Violência Doméstica e Familiar contra a Mulher ocorre a partir da transformação de estruturas já existentes, sem as mudanças necessárias na organização judiciária, no orçamento ou nas leis, de forma a prover recursos humanos e equipe multidisciplinar compatível com as atividades que deverão ser realizadas. $\mathrm{O}$ desempenho dessa dupla competência, por conseguinte, tem sido parcial, limitada às medidas de proteção para a mulher e medidas cautelares, de caráter provisório, nas questões envolvendo os filho(a)s, deixando que a decisão de recorrer à Justiça de Família ou Cível recaia sobre a mulher. Quanto às ações criminais, a crença amplamente disseminada entre os operadores do Direito - juízes(as) e promotores(as) de justiça - de que as mulheres não desejam a punição para os seus agressores, tem resultado, em grande parte das vezes, em arquivamento das denúncias ou — novamente - suspensão condicional do processo (OBSERVE, 2010).

O problema, pois, não reside na incidência ou não da suspensão condicional do processo, mas em ações efetivas de abordagem multidisciplinar. Isso pode se dar no bojo de uma suspensão condicional do processo, mas a incidência e a relevância dessa intervenção mostram-se muitíssimo mais relevantes que a sua vinculação com o instituto despenalizante. A razão, repita-se, é singela: as ações multidisciplinares mostram-se muito mais eficazes para o enfrentamento da violência doméstica e familiar contra a mulher que a solução daquele específico processo- crime ensejador da intervenção do Estado. 
Os esforços de conformação do Protocolo Regional para a Investigação com Perspectiva de Gênero dos crimes de Violência Doméstica e Familiar contra as Mulheres são no mesmo sentido. A Conferência de Ministros de Justiça dos países ibero-americanos COMJIB e a Asociación Ibero-americana de Ministerios Públicos — AIAMP desenvolveram, em parceria com o Programa para la Cohesión Social em America Latina EUROsociAL elaboraram o "Protocolo Regional para a investigação com perspectiva de gênero dos crimes de violência contra as mulheres cometidos no âmbito intrafamiliar" que estabelece os parâmetros mínimos necessários para a incorporação da perspectiva de gênero pelas instituições responsáveis pela investigação e processamento de crimes de violência contra as mulheres". Nele, encontra-se um texto-base para que diferentes Estados e instituições competentes para a promoção de investigação criminal desenvolvam instrumentos adequados de padronização de atendimento, atenção e proteção às mulheres em situação de violência de doméstica e familiar, adaptados às diferentes realidades e ao tratamento específico que a matéria impõe para garantir o direito humano das mulheres de viver livre de violência. No Brasil, esse esforço culminou na "Versão adaptada do Protocolo Regional para a Investigação com Perspectiva de Gênero dos crimes de Violência Doméstica e Familiar contra as Mulheres”.

No Protocolo Regional, são destacadas as ações de caráter multidisciplinar e de caráter mais amplo da intervenção estatal, de modo que a resposta ao fenômeno da violência doméstica e familiar contra a mulher não se limite ou não se reduza à simples persecução penal do agressor. Demais disso, o aprimoramento dos instrumentos de Estado para essa abordagem passam pela sensibilização de gênero dos operadores, pela formação continuada desses profissionais, pela atenção específica às mulheres particularmente vulneráveis em situação doméstica e familiar e dotação de práticas multidisciplinares diretamente nos órgãos incumbidos da persecução penal, numa atuação integrada e articulada (BRASIL, Ministério da Justiça: 2014).

A resposta penal, portanto, mostra-se importante. Contudo, não é nela que devam se fiar exclusivamente as ações de caráter multidisciplinar de caráter mais amplo e efetivo para o enfrentamento da violência doméstica e familiar contra a mulher. Por isso, conquanto não se perca de vista a importância das consequências jurídico-processuais para a ausência de instrumentos despenalizantes ou que afastem o processo-crime decorrente da ação violenta em desfavor da mulher, deve- se ter em relevo que as práticas interventivas devem ser fomentadas em concurso com a resposta penal do Estado, jamais solitariamente ou a par dessa resposta própria do aparato repressivo estatal. 
De um lado, o Estado por seus atos normativos expressamente reconhece o problema da violência de gênero como uma questão complexa, que requer um olhar atento das entidades governamentais, não-governamentais e da sociedade como um todo. De outro lado, há a dificuldade material, própria da necessidade de aprimoramento de ações articuladas nas esferas estatais, para que se concretizem os rumos fixados pela Lei Maria da Penha. Não há como atuar eficazmente com um enfoque exclusivamente voltado às vítimas, pois uma ação multidisciplinar de caráter interventivo deve igualmente primar pela abordagem igualmente dos fatores reais de risco da vítima e isso, decerto, inclui a intervenção em relação ao agressor igualmente. Não há como privilegiar unicamente o aspecto punitivo da legislação, com a consequente estigmatização dos agressores como réus, se olvidando das mais variadas questões que circundam essa violência. A pretensão de enfrentamento da violência doméstica e familiar contra a mulher de modo efetivo passa pela concretização de ações e políticas que acolham a mulher vítima da violência e, igualmente, a pessoa do agressor.

Trata-se de um dos aparentes paradoxos da Lei Maria da Penha. De um lado, a condução dos agressores para programas de atendimento psicossocial unicamente como forma de sentença e execução penal. De outro lado, o Título $\mathrm{V}$ da Lei está voltado à criação de equipes de atendimento multidisciplinar para desenvolver trabalhos de orientação e prevenção, não apenas para as ofendidas e seus familiares, mas para os agressores também. Daí a necessidade de adoção de respostas que permitam o encaminhamento ainda no curso da persecução penal, sem que isso implique a suspensão condicional do processo, pois legalmente vedada.

Ainda que se afirme que a aplicação da suspensão condicional do processo, com o consequente encaminhamento dos agressores a unidades de recuperação e reeducação, implique retardamento na solução do processo penal, a prática demonstra o contrário. A possibilidade de oferecimento da suspensão condicional do processo retrata a pronta intervenção do Estado, viabilizando a celeridade que as delongas de um processo criminal impedem. Isso tudo, claro, desde que a suspensão condicional do processo seja acompanhada de práticas de caráter multidisciplinar, dado que a simples imposição de período de prova sem ações interventivas significam para o conflito resposta mais gravosa que a ausência de resposta.

As chances de êxito na atuação do Estado reduzida ao encarceramento dos agressores mostram-se diminutas no enfrentamento da questão a médio e longo prazo. A simples imposição da prisão não traduz uma intervenção comprometida com a responsabilização do agressor no sentido de mobilizá-lo para um processo de mudanças de valores e comportamentos 
nas relações de gênero, a fim de prevenir novas agressões. A garantia de que os agressores se submeterão ao acompanhamento em unidades dirigidas para reabilitação e reeducação, sem a incidência do instituto da suspensão condicional do processo, deve se materializar por respostas outras, que guardem ações articuladas e integradas dos órgãos de persecução penal.

Ressalta-se a importância das políticas educativas: elas podem influenciar positivamente numa mudança social dos supostos agressores — considerando as diversidades de geração, de singularidades regionais e culturais, de condições econômicas. Um trabalho publicado pelo Instituto PAPAI denominado de "Princípios, diretrizes e recomendações para uma atenção integral aos homens na saúde”, indicou a importância de encarar o tópico da violência de gênero também como uma questão de saúde pública, e não só jurídica ou de segurança pública. Apontou ser fundamental a inserção de ações concomitantes e intersetoriais, seja de caráter preventivo ou na atenção adequada aos autores de violência (INSTITUTO PAPAI: 2010).

Há outras pesquisas que trazem dados com resultados satisfatórios para ações dirigidas aos agressores. Os chamados grupos de reflexão, criados como uma alternativa para se trabalhar a desigualdade de gênero, constituem bom exemplo. Em dados divulgados pelo Juizado Especial Criminal da Violência Doméstica contra a Mulher de São Gonçalo (RJ), no ano de 2013, constatou-se que dos homens que praticaram violência contra mulher e participam de grupos de reflexão, menos de $2 \%$ voltaram a agredir suas companheiras. No mesmo sentido, um grupo reflexivo voltado para homens agressores que funcionava em São Caetano (ABC Paulista), entre 2006 e 2008, apontou que participaram da ação 56 homens, sendo que houve apenas um caso de reincidência e três casos de abandono. Em contrapartida, uma pesquisa empreendida na Vara Especial de Violência Doméstica e Familiar contra a Mulher, de São Luiz (MA), onde não havia grupos voltados para os homens até 2009, apontou que $75 \%$ dos agressores eram reincidentes (BIANCHINI: 2013). Atualmente, os grupos para homens autores de violência contra a mulher são compostos por aqueles que procuraram espontaneamente o serviço, que foram encaminhados de forma compulsória pela Justiça e os que foram enviados de forma não compulsória por outros serviços da rede de atendimento.

Desse modo, os homens, como sujeitos-parte das relações violentas, merecem considerações que vão além do rótulo de "agressor". A comunidade masculina precisa ser ouvida e igualmente figurar como destinatária de ações preventivas. A partir dessa preocupação, ganham relevo trabalhos educativos, reflexivos e preventivos, direcionados a lidar com um problema complexo e antigo, que acompanha os passos de uma sociedade vinculada ao 
patriarcado. As pessoas envolvidas nas relações de violência precisam abraçar o desejo de mudar. É importante que comecem a compartilhar seus problemas afetivos e familiares, que reconheçam as dificuldades de manter essas relações, que despertem para repensar seus papéis, comportamentos e valores, para que suas visões de mundo sejam ampliadas em busca da tão buscada igualdade de gênero.

\section{CONCLUSÃO}

A Lei Maria da Penha destaca-se como diploma legal que estabelece o marco normativo para o enfrentamento da violência doméstica e familiar contra a mulher no Brasil. Em atenção a Convenções e Tratados Internacionais, a Lei de 2006 estabelece um sistema protetivo em favor da mulher e, principalmente, estabelece um sistema normativo que se opõe ao patriarcado, de modo a assegurar visibilidade ao fenômeno da violência doméstica e familiar contra a mulher.

A Lei fez a opção político-criminal de afastar a incidência dos institutos despenalizadores previstos para os Juizados Especiais Criminais. O destaque à proibição de incidência da suspensão condicional do processo lançou luz à questão sobre o modo pelo qual, dentro da persecução penal, devem incidir as ações interventivas de caráter multidisciplinar. Independentemente da proibição de incidência da suspensão condicional do processo, a incidência de ações de caráter multidisciplinar mostra-se tão ou mais relevante que a própria resposta penal em si para o fenômeno da violência doméstica e familiar contra a mulher.

A par da resposta penal formalizada pelo Estado, para fins de responsabilização do agressor, a intervenção bem sucedida no fenômeno da violência doméstica e familiar contra a mulher deve guardar perspectiva mais ampla, de modo a se dirigir não apenas à mulher em situação de violência mas igualmente ao agressor. Somente essa abordagem mais ampla, de prestígio à resposta multidisciplinar, tem aptidão de assegurar uma resposta eficaz em relação à prevenção de novos episódios de violência e de construção de um quadro em que a superação desse tipo de violência passe a ser uma realidade hábil a ser vista num horizonte possível. 


\section{REFERÊNCIAS}

BRANCO, Ana L. U. de A.; ALMEIDA, Tânia M. C. A prática do psicólogo em atendimento a famílias em situação de violência. In: ALMEIDA PENSO, Maria A.; ALMEIDA, Tânia M. C. (Org.). Direitos e conflitos psicossociais: ações e interfaces disciplinares. São Paulo: Rocca, 2012.

BRASIL. Constituição da República Federativa do Brasil de 1988. Texto compilado. Disponível em

<http://www.planalto.gov.br/ccivil_03/Constituicao/ConstituicaoCompilado.htm>.

Acesso em 1. ${ }^{\circ}$ out. 2015.

- Ministério da Justiça. Versão adaptada do Protocolo Regional para a Investigação com Perspectiva de Gênero dos crimes de Violência Doméstica e Familiar contra as Mulheres. Brasília: Programa para la Cohesión Social en America Latina (EUROsociAL), 2014.

http://www.compromissoeatitude.org.br/wp-

Disponível em

content/uploads/2016/04/EUROsociAL_DiretrizesInvestigacaoPerspectivaGenero201

5.pdf >. Acesos em 1. ${ }^{\circ}$ out. 2015.

- Senado Federal. Comissão Parlamentar Mista de Inquérito "Com a finalidade de investigar a situação da violência contra a mulher no Brasil e apurar denúncias de omissão por parte do poder público com relação à aplicação de instrumentos instituídos em lei para proteger as mulheres em situação de violência". Relatório Final. Julho de 2013. Disponível em: $<$ http://www.senado.gov.br/atividade/materia/getPDF.asp?t=131554\&tp=1>. Acesso em 1 . $^{\circ}$ out. 2015.

BRASIL. Superior Tribunal de Justiça. Terceira Seção. Súmula 536. “A suspensão condicional do processo e a transação penal não se aplicam na hipótese de delitos sujeitos ao rito da Lei Maria da Penha". Julgamento em 10 jun. 2015. Diário de Justiça Eletrônico de 15 jun. 2015. Disponível em <http://www.stj.jus.br/>. Acesso em 1. out. 2015.

BRASIL. Supremo Tribunal Federal. Tribunal Pleno. Ação Declaratória de Constitucionalidade n. 19. Distrito Federal. Relatoria Ministro Marco Aurélio. Julgamento em 9 fev. 2012. Diário de Justiça Eletrônico de 29 abr. 2014. Disponível em <http://www.stf.jus.br/>. Acesso em 1. ${ }^{\circ}$ out. 2015. Disponível em <http://www.stf.jus.br/>. Acesso em 1. ${ }^{\circ}$ out. 2015.

BRASIL. Supremo Tribunal Federal. Tribunal Pleno. Ação Direta de Inconstitucionalidade n. 4424. Distrito Federal. Relatoria Ministro Marco Aurélio. Julgamento em 9 fev. 2012. Diário de Justiça Eletrônico de 1. ${ }^{\circ}$ ago. 2014. Disponível em <http://www.stf.jus.br/>. Acesso em 1. ${ }^{\circ}$ out. 2015.

BIANCHINI, Alice. Homens agressores: grupos de reflexão, prevenção terciária e violência doméstica. 2013. Disponível em:

$<$ http://professoraalice.jusbrasil.com.br/artigos/121814321/homens-agressores- grupos-dereflexao-prevencao-terciaria-e-violencia-domestica>. Acesos em 1. ${ }^{\circ}$ out. 2016. 
Quais são as razões da violência doméstica contra a mulher? Com a palavra, a vítima. 2011. Disponível em:

$<\mathrm{http}$ //professoraalice.jusbrasil.com.br/artigos/121814043/quais-sao-as-razoes-daviolencia-domestica-contra-a-mulher-com-a-palavra-a-vitima>. Acesso em 1. ${ }^{\circ}$ out. 2015 .

CARVALHO, Luis Gustavo G. C. de; PRADO, Geraldo. Lei dos Juizados Especiais. Rio de Janeiro: Lumen Juris, 2003.

CERQUEIRA, Daniel; MATOS, M. V. M; MARTINS, A. P. A.; PINTO JÚNIOR, J. Avaliando a efetividade da Lei Maria da Penha. Texto para discussão. Brasília: Instituto de Pesquisa Econômica Aplicada - IPEA, março de 2015. Disponível em:

<http://www.ipea.gov.br/portal/images/stories/PDFs/TDs/td_2048k.pdf $>$. Acesso em 1. ${ }^{\circ}$ out. 2015 .

CAVALCANTI, Carla Adriana de Carvalho. Suspensão condicional do processo (art. 89 da Lei 9.099/95): benefício ou constrangimento?. 2012. Disponível em:

<http://www.esdc.com.br/RBDC/RBDC-19/RBDC-19-

401Monografia_Carla_Adriana_de_Carvalho_Cavalcanti_(Suspensao_Condicional_

do_Processo_Beneficio_ou_Constrangimento).pdf >.

CUNHA, José Ricardo et al. Direitos Humanos e Poder Judiciário no Brasil: Federalização, Lei Maria da Penha e Juizados Especiais Federais. Rio de Janeiro: FGV Direito Rio, 2010, 150 p.

FERNANDES, Antonio Scarance. Processo penal constitucional. 6. ed. revista atualizada e ampliada. São Paulo: RT, 2010.

IBOPE; THEMIS - ASSESSORIA JURÍDICA E ESTUDOS DE GÊNERO. Dois anos da Lei Maria da Penha: o que pensa a sociedade? 2008. Disponível em:

$<$ http://agenciapatriciagalvao.org.br/wp-

content/uploads/2009/08/pesq_ibope_2008.pdf>. Acesso em 1. ${ }^{\circ}$ out. 2015.

INSTITUTO DE ESTUDOS SOCIOECONÔMICOS (INESC). Ligue 180 registra 53\% de risco de morte em relatos de violência contra as mulheres. 2 mai. 2012. Disponível em: $<$ http://www.inesc.org.br/noticias/noticias-gerais/2012-1/maio/ligue-

180-registra-53-de-risco-de-morte-em-relatos-de-violencia-contra-as-mulheres>. Acesso em $1 .^{\circ}$ out. 2015.

INSTITUTO PAPAI. Homens e masculinidades: práticas de intimidade e políticas públicas. $2010 . \quad$ Disponível em:

<http://www.unfpa.org.br/Arquivos/homens_masculinidades.pdf >. Acesso em 1. ${ }^{\circ}$ out. 2015 .

MORIÉRE, Laisy. Políticas Públicas e combate à violência contra a mulher. 24 nov. 2011. Disponível em: <http://novo.fpabramo.org.br/content/politicas-publicas-e- combateviolencia-contra-mulher>. Acesso em 1. ${ }^{\circ}$ out. 2015. 
OBSERVE. Pesquisa sobre Condições de aplicação da Lei 11.340/2006 (Lei Maria da Penha) nas Delegacias Especializadas de Atendimento a Mulher (DEAMs) e Juizados de Violência Doméstica e Familiar nas capitais e DF. Relatório Final. Dezembro de 2010. Salvador: UFBA.

ORGANIZAÇÃO DA NAÇÕES UNIDAS (ONU). Convenção Interamericana para prevenir, punir e erradicar a violência contra a mulher - "Convenção de Belém do Pará" (1994). Adotada em Belém do Pará, Brasil, em 9 de junho de 1994, no Vigésimo Quarto Período Ordinário de Sessões da Assembleia Geral. Disponível em <http://www.cidh.org/Basicos/Portugues/m.Belem.do.Para.htm>. Acesso em 1. ${ }^{\circ}$ out. 2015.

ORGANIZAÇÃO DOS ESTADOS AMERICANOS (OEA). Comissão Interamericana de Direitos Humanos. Convenção sobre a eliminação de todas as formas de discriminação contra a mulher (CEDAW - 1979). Adotada pela Resolução n. 34/180 da Assembleia Geral das Nações Unidas em 18 de dezembro de 1979 e ratificada pelo Brasil em $1 .^{\circ}$ de fevereiro de 1984. Disponível em <http://www.unicef.org/brazil/pt/resources_10233.htm>. Acesso em 1. ${ }^{\circ}$ out. 2015.

PRATES, Paula L.; ANDRADE, Leandro F. Grupos reflexivos como medida judicial para homens autores de violência contra a mulher: o contexto sócio-histórico. In: Seminário Internacional Fazendo Gênero 10 (Anais Eletrônicos), Florianópolis, 2013. ISSN 2179-510X. Disponível em:

<http://www.fazendogenero.ufsc.br/10/resources/anais/20/1386779075_ARQUIVO_ PaulaLicursiPrates.pdf $>$. Acesso em 1. ${ }^{\circ}$ out. 2015.

SAFFIOTI, Heleieth I. B. Gênero, patriarcado, violência. São Paulo: Fundação Perseu Abramo, 2004.

SOARES, Barbara Musumeci. A "conflitualidade" conjugal e o paradigma da violência contra a mulher. In: DILEMAS: Revista de Estudos de Conflito e Controle Social. Vol. 5, n. 2, abr/mai/jun 2012, p. 191-210. Disponível em: <http://revistadil.dominiotemporario.com/doc/dilemas-5-2-art1.pdf >. Acesso em 1. ${ }^{\circ}$ out. 2015.

WAISELFISZ, Julio Jacobo. Mapa da Violência 2012: Atualização: Homicídio de Mulheres no Brasil. [s.1.]: Flacso Brasil; CEBELA, 2012. Disponível em <http://www.mapadaviolencia.org.br/pdf2012/MapaViolencia2012_atual_mulheres.pdf>. Acesso em 1. ${ }^{\circ}$ out. 2015. 